\title{
Factors associated with postoperative hypocalcemia following surgery for thyroid cancer in childhood
}

\author{
Claudio Spinelli ${ }^{1}$, Marco Ghionzoli ${ }^{1}$, Alessia Bertocchini ${ }^{1}$, Beatrice Sanna ${ }^{1}$, Carlotta \\ Plessi $^{2}$, Luigi De Napoli ${ }^{1}$, Gianluca Frustaci ${ }^{1}$, Gabriele Materazzi ${ }^{1}$, Alessandro Antonelli ${ }^{1}$, \\ Fabrizio Gennari ${ }^{3}$, Alessandro Inserra ${ }^{4}$, Gianni Bisogno ${ }^{5}$, Piergiorgio Gamba ${ }^{5}$, Andrea \\ Ferrari $^{6}$, and Maura Massimino ${ }^{6}$ \\ ${ }^{1}$ University of Pisa \\ ${ }^{2}$ University of Siena \\ ${ }^{3}$ Regina Margherita Children's Hospital \\ ${ }^{4}$ Ospedale Pediatrico Bambino Gesù \\ ${ }^{5}$ University of Padua \\ ${ }^{6}$ Fondazione IRCCS Istituto Nazionale dei Tumori
}

June 1, 2021

\begin{abstract}
Background: Postoperative hypocalcemia is a frequent complication after thyroid surgery. Hypoparathyroidism may develop as transient (TtHP), with normalization within six months from surgery, or permanent (PtHP) if the patient requires replacement therapy. The present study analyzes rates and factors associated with the development of TtHP or PtHP following thyroid surgery in a pediatric population. Procedure: A retrospective multicenter study analyzing 363 patients was carried out. We recorded gender, age, tumor size, type of surgery, lymph node dissection, histology. Calcium levels were acquired daily for 72 hours after discharge. Subsequent sample collection was customized on the patient's hypocalcemia severity. Results: We analyzed 363 patients aged [?]18 years (mean age 14.2 years) who underwent thyroid surgery clustered into age groups ([?]15 or $>15)$. Patients mean follow-up was 5.8 years (1-11yrs). At histology 310 (85\%) were papillary carcinoma, 32 (9\%) were follicular carcinoma, $6(2 \%)$ presented diffuse sclerosing variant of papillary thyroid carcinoma whilst $15(4 \%)$ had familial medullary carcinoma. TtHP developed in $36(9,9 \%)$, PtHP in $20(5.5 \%)$ cases. TtHP was more frequent in younger patients $(\mathrm{p}=0,009)$. Both PtHP and TtHP were increased in case of larger tumors ([?]2 cm) $(\mathrm{p}=0,001)$. All TtHP and PtHP were in TT group. PtHP rate was increased if lymph node dissection was carried out $(\mathrm{p}<0.001)$. Conclusions: The risk of hypoparathyroidism is related to younger age, tumor size, TT and lymph node dissection therefore surgeons should tailor surgery as much as possible to avert such complication.
\end{abstract}

\section{Introduction}

Along with the recurrent laryngeal nerve paralysis and bleeding, postoperative hypocalcemia is the major and most frequent complication that occurs after thyroid surgery ${ }^{1}$. Commonly it arises following removal or insult to the parathyroid glands at neck surgery ${ }^{2-6}$. Hypoparathyroidism is defined by a decrease in serum PTH and calcium levels: it may occur as a transient form (TtHP), with progressive normalization within six months from surgical treatment, or permanent (PtHP), whenever the patient continues to require replacement therapy ${ }^{7,8}$. Numerous reports have attempted to correlate the incidence of post surgical complications with the type of thyroid disease associated, positive family history of thyroid cancer, gender of the patient, type of operation, cervical lymph nodes involvement, surgical expertise and surgical timing ${ }^{6,9-13}$. The identification of fewer than two parathyroid glands during thyroidectomy is also associated with the devel- 
opment of hypocalcemia ${ }^{14}$. Others have investigated the possible link between the development of transient hypocalcemia and low levels of preoperative vitamin $\mathrm{D}$ associated with low postoperative parathyroid hormone (PTH) ${ }^{15-22}$. Another biochemical parameter which has been correlated with transient hypocalcemia is the post-operative serum magnesium concentration, independently of the serum calcium levels ${ }^{23-26}$. The calcium level less than $1.88 \mathrm{mmol} / \mathrm{l}$ or lower after $24 \mathrm{~h}$ from thyroid surgery has been reported as predictive for the development of permanent hypocalcemia ${ }^{27-32}$. The risk factors identified by the scientific community are different, depending on TtHP or PtHP and are currently a matter of debate. In the present study the main end-point was to analyze, in a pediatric population following thyroid surgery, rate and factors associated with the development of TtHP or PtHP.

\section{Methods}

This retrospective multicenter study analyzes pediatric patients, operated over a 11 year period (January 2009 - December 2019) at several institutions (Division of Paediatric Surgery and Division of Endocrine Surgery at University of Pisa, Division of Pediatric Surgery at "Regina Margherita Hospital" in Turin, General Pediatric and Thoracic Surgery at Bambino Gesù Children's Hospital-Research Institute in Rome, Pediatric Surgery at Department of Woman and Child Health in Padua and the National Cancer Institute in Milan).

The variables taken into consideration are: gender, age, tumor size, type of surgery performed (total thyroidectomy - TT or hemithyroidectomy - HT), autotransplantation into the ipsilateral sternocleidomastoid muscle in case of incidental parathyroidectomy, lymph node dissection, histology (papillary carcinoma, diffuse sclerosing variant, follicular carcinoma, medullary carcinoma within genetic forms, such as MEN2A, MEN2B and FMTC). The age range at the operation was $4-18$, with a mean age of 13.6 years. The exclusion criteria were: primitive hypoparathyroidism, low levels of vitamin D, low calcium level measured preoperatively, previous parathyroidectomy due to hyperparathyroidism or patients who received supplementary calcium treatment due to other causes. Follow-up after surgery consisted of measuring serum calcium levels by blood sampling. Post-operative hypocalcemia was defined as a serum calcium level of less than $8 \mathrm{mg} / \mathrm{dl}$. The first measurement was made within 24 hours after the operation. A serum level check was repeated once a day in the three days following discharge. Postoperative parathyroid hormone (PTH) levels were determined in case of persistent low serum calcium levels ${ }^{33-34}$. In patients with serum calcium levels $<8 \mathrm{mg} / \mathrm{dl}$ with or without associated symptoms, intravenous or oral calcium was administered. In case of persistent hypocalcemia, subsequent serum calcium samples were drawn, with a frequency ranging from one per week to one per month ${ }^{4}$. Calcium supplementation doses were adjusted during follow-up according to symptoms and serum calcium levels ${ }^{35}$. TtHP was considered when patients received calcium supplementation and/or had a normalization in PTH levels within 6 months after surgical treatment. PtHP was defined as the need for calcium supplementation with or without active Vitamin D even 6 months after surgery ${ }^{7}$.

\section{Statistical Analysis}

The categorical data were summarized with the absolute and percentage frequency. To compare the percentages of hypoparathyroidism, both in terms of transient and permanent, the z-test for proportions was used, so as to allow observing whether the pathology is randomly distributed or preferentially between the two variables examined. The significance was set at $0.05(\mathrm{p}<0.05)$. All analyzes were performed with SPSS technology v. 26.

\section{Results}

We analyzed 363 patients aged [?]18 years (mean age 14.2 years) who underwent surgery due to thyroid carcinoma: 210 males (58\%), females $153(42 \%)$. We clustered patients into age groups: [?] 15 years or > 15 years. In the first subgroup we included 207 cases (57\%) while $156(43 \%)$ were older. All the patients underwent a mean follow-up of 5.8 years (range 1-11 years). We grouped the patients according to the tumor size: in $210(57 \%)$ cases the tumor was $<2 \mathrm{~cm}$, while in $153(42 \%)$ it was [?] $2 \mathrm{~cm}$. Three hundred twenty six patients $(90 \%)$ underwent total thyroidectomy, $37(10 \%)$ a hemithyroidectomy. Lymph node dissection was carried out in 175 (48\%) patients. In 16 cases (4\%), due to incidental parathyroidectomy, we performed an 
autotransplantation into the ipsilateral sternocleidomastoid muscle. At histological examination 310 (85\%) were papillary carcinoma in the classical variant, $32(9 \%)$ were follicular carcinoma, $6(2 \%)$ presented diffuse sclerosing variant of papillary thyroid carcinoma whilst 15 (4\%) had medullary carcinoma: 6 MEN 2A (2\%), 4 MEN 2B (1\%), 5 FMTC (1\%). TtHP developed in 36 (10\%), PtHP in $20(6 \%)$ cases. No significant differences between TtHP and PtHP groups were reported with regard to gender $(\mathrm{p}=0.408$ for TtHP and $\mathrm{p}=0.974$ for PtHP) and parathyroid autotransplantation ( $\mathrm{p}=0.437$ for TtHP and $\mathrm{p}=0.673$ for PtHP). TtHP was more frequent in subjects with age [?]15 years $(\mathrm{p}=0.009)$. Both PtHP and TtHP were increased in case of larger tumors $([?] 2 \mathrm{~cm})(\mathrm{p}=0.001)$. Concerning surgical approach, all the patients who presented TtHP and PtHP belonged to the TT group. PtHP rate was increased in patients who underwent lymph node dissection $(\mathrm{p}<0.001)$. No significant histologic differences for TtHP and PtHP were reported. Table 1 and 2 report the statistical analysis performed on all the parameters we investigated in our cohort of patients.

\section{Discussion}

Hypocalcemia is one of the most frequent complications of thyroid surgery, due to decreasing PTH levels following surgery associated with intraoperative ischemia and/or reduction in volume of parathyroid glands or incidental parathyroidectomy ${ }^{36}$. To date, few studies focused on hypocalcemia following thyroid surgery in children and adolescents, analyzing the possible predictive factors of this complication ${ }^{5,36-42}$. In reported case-series TtHP incidence ranges from $13.6 \%$ to $34 \%{ }^{43-44}$ following total thyroidectomy in pediatric age. Nordenström et al. ${ }^{45}$ report that out of 274 patients, below 18 years of age undergoing thyroidectomy, 7.3\% developed PtHP, while Klein Hesselink et al. ${ }^{30}$, analyzed 105 patients aged [?]18 years operated for differentiated thyroid cancer and reported that $23.8 \%$ of patients developed PtHP. Our data demonstrated that both TtHP and PtHP incidences are in line with current literature ${ }^{30,43-46}$. Scholtz et al. ${ }^{47}$ mention the existence of a female prevalence for postoperative hypoparathyroidism, linked to greater susceptibility to thyroid diseases. On the contrary, in our study, gender was not a determining factor in predicting the risk of developing these complications. De Groot JW et al. ${ }^{48}$, confirmed by Kluijfhout WP ${ }^{49}$ et al. and Moley JF et $\mathrm{al}^{50}$, showed that the smaller the age of the patients, the greater is the probability of developing postoperative hypoparathyroidism, due to the difficulty in identifying parathyroid glands during surgery or due to the greater fragility of the anatomical structures. The data we analyzed are in agreement with what was discussed above: patients with age [?]15 years have a significantly greater risk of developing TtHP; with regard to PtHP, data do not suggest any age-based difference. Younger children have a greater ability to recover from TtHP; in fact, in our series, two thirds of patients affected by postoperative hypocalcemia completely recovered. Patients between 16 and 18 years of age are less likely to recover, since all patients with TtHP developed PtHP. In our study, tumor size is associated with postoperative hypocalcemia: TtHP is more frequent in tumors [?] $2 \mathrm{~cm}$ and size seems to be even more relevant for PtHP. TT behaves as a positive predictive factor for hypocalcemia with regards to low volume surgeons, as shown by Hauch et al. ${ }^{51}$ confirmed by Sosa ${ }^{9}$. In our series, this complication occurred only in patients who underwent TT, we report no hypocalcemia related to HT; however Newman et al. ${ }^{52}$ reported 9 cases (11\%) of hypoparathyroidism out of 82 patients analyzed aged [?]21 years, who underwent lobectomy. In the present study, lymph node dissection seems to assume a fundamental role for PtHP; the reasons behind this might reside in the wider resection performed or the prolonged duration of surgery, which is in line with current literature ${ }^{53}$. With reference to the histotype as a predictor for the development of hypocalcemia in children, Scholz et al. ${ }^{47}$ identify PTC to be the most common, but in our experience this data does not reach significance. During surgery it is crucial to carry out a meticulous dissection aimed at preserving parathyroid glands and keeping their vascularization intact; a fundamental factor for post-operative normocalcemia is the preservation of at least three parathyroid glands in situ after surgery ${ }^{54}$. In order to prevent postoperative hypoparathyroidism, in case of inadvertent parathyroidectomy, parathyroid autotransplantation may be performed ${ }^{55,56}$, even though its effective utility has been questioned ${ }^{57}$. We did not report any significant difference for what concerns parathyroids autotransplantation in TtHP and PtHP groups.

\section{Conclusions}

From the data obtained from our work, we found an association of TtHP with the age at which the patients 
underwent surgery and the size of the tumor, while the size of the tumor and the lymph node dissection are associated with the development of PtHP. Moreover, no patients who have undergone HT presented with TtHP or PtHP. This might suggest that children, operated for thyroid cancer, should be treated with the least invasive surgical approach possible, in order to reduce the risk of development of hypoparathyroidism.

\section{Conflict of interest}

All the authors confirm they have no conflicts of interest or competing interests to disclose.

\section{References}

${ }^{1}$ Mannstadt M, Bilezikian JP, Thakker RV, et al. Hypoparathyroidism [published correction appears in Nat Rev Dis Primers. 2017 Oct 05;3:17080]. Nat Rev Dis Primers. 2017;3:17055. ${ }^{2}$ Asari R, Passler C, Kaczirek K, Scheuba C, Niederle B. Hypoparathyroidism after total thyroidectomy: a prospective study. Arch Surg. 2008;143(2):132-138. ${ }^{3}$ Kakava K, Tournis S, Papadakis G, et al. Postsurgical Hypoparathyroidism: A Systematic Review. In Vivo. 2016;30(3):171-179. ${ }^{4}$ Brandi ML, Bilezikian JP, Shoback D, et al. Management of Hypoparathyroidism: Summary Statement and Guidelines. J Clin Endocrinol Metab. 2016;101(6):2273$2283 .{ }^{5}$ Spinelli C, Bertocchini A, Antonelli A, Miccoli P. Surgical therapy of the thyroid papillary carcinoma in children: experience with 56 patients $<$ or $=16$ years old. J Pediatr Surg. 2004; 39(10):1500-1505. ${ }^{6}$ Massimino M, Evans DB, Podda M, Spinelli C et al. Thyroid cancer in adolescents and young adults. Pediatr Blood Cancer. 2018;65(8):e27025. ${ }^{7}$ Spinelli C, Strambi S, Rossi L, et al. Surgical management of papillary thyroid carcinoma in childhood and adolescence: an Italian multicenter study on 250 patients. J Endocrinol Invest. 2016;39(9):1055-1059. ${ }^{8}$ Freire AV, Ropelato MG, Ballerini MG, et al. Predicting hypocalcemia after thyroidectomy in children. Surgery. 2014;156(1):130-136. ${ }^{9}$ Sosa JA. What's old is new again : editorial about "total thyroidectomy is associated with increased risk of complications for low- and high-volume surgeons," by Hauch et al., doi:10.1245/s10434-014-3846-8. Ann Surg Oncol. 2014;21(12):3719-3720. ${ }^{10}$ Spinelli C, Strambi S, Bakkar S, et al. Surgical Management of Diffuse Sclerosing Variant of Papillary Thyroid Carcinoma. Experience in 25 Patients. World J Surg. 2020; 44(1):155-162. ${ }^{11}$ Spinelli C, Piccolotti I, Bertocchini A, et al. Familial Non-Medullary Thyroid Carcinoma in Pediatric Age: Our Surgical Experience [published online ahead of print, 2021 Apr 23]. World J Surg. 2021; 10.1007/s00268-021-06104-5. ${ }^{12}$ Memeh K, Ruhle B, Alsafran S, et al. Total Thyroidectomy vs Thyroid Lobectomy for Localized Papillary Thyroid Cancer in Children: A Propensity-Matched Survival Analysis [published online ahead of print, 2021 Apr 3]. J Am Coll Surg. 2021;S1072-7515(21)00241-6. ${ }^{13}$ Thankamony P, Nirmal G, Chandar R, Nair AKR, Veeramoni Iyer Mriduladevi P. Differentiated thyroid carcinoma in children: A retrospective analysis of 125 pediatric cases from a single institution in India [published online ahead of print, 2021 Apr 26]. Pediatr Blood Cancer. 2021; e29076. ${ }^{14}$ Erbil Y, Barbaros U, Temel B, et al. The impact of age, vitamin $\mathrm{D}(3)$ level, and incidental parathyroidectomy on postoperative hypocalcemia after total or near total thyroidectomy. Am J Surg. 2009; 197(4):439-446. ${ }^{15}$ Erbil Y, Ozbey NC, Sari S, et al. Determinants of postoperative hypocalcemia in vitamin D-deficient Graves' patients after total thyroidectomy. Am J Surg. 2011;201(5):685-691. ${ }^{16}$ Park I, Rhu J, Woo JW, Choi JH, Kim JS, Kim JH. Preserving Parathyroid Gland Vasculature to Reduce Postthyroidectomy Hypocalcemia. World J Surg. 2016; 40(6):1382-1389. ${ }^{17}$ Yamashita H, Noguchi S, Murakami $\mathrm{T}$, et al. Calcium and its regulating hormones in patients with graves disease: sex differences and relation to postoperative tetany. Eur J Surg. 2000;166(12):924-928. ${ }^{18}$ Kirkby-Bott J, Markogiannakis H, Skandarajah A, Cowan M, Fleming B, Palazzo F. Preoperative vitamin D deficiency predicts postoperative hypocalcemia after total thyroidectomy. World J Surg. 2011; 35(2):324-330. ${ }^{19}$ Chincholikar SP, Ambiger S. Association of Hypomagnesemia with Hypocalcemia after Thyroidectomy. Indian J Endocrinol Metab. 2018; 22(5):656$660 .{ }^{20}$ Amir A, Sands NB, Tamilia M, Hier MP, Black MJ, Payne RJ. Preoperative serum calcium levels as an indicator of post thyroidectomy hypocalcemia. J Otolaryngol Head Neck Surg. 2010; 39(6):654-658. ${ }^{21}$ Graff AT, Miller FR, Roehm CE, Prihoda TJ. Predicting hypocalcemia after total thyroidectomy: parathyroid hormone level vs. serial calcium levels. Ear Nose Throat J. 2010; 89(9):462-465. ${ }^{22}$ Asari R, Passler C, Kaczirek K, Scheuba C, Niederle B. Hypoparathyroidism after total thyroidectomy: a prospective study. Arch Surg. 2008; 143(2):132-138. ${ }^{23}$ Costanzo M, Marziani A, Condorelli F, Migliore M, Cannizzaro MA. Post-thyroidectomy hypocalcemic syndrome: predictive value of early PTH. Preliminary results. Ann Ital 
Chir. 2010; 81(4):301-305. ${ }^{24}$ Mehrvarz S, Mohebbi HA, Kalantar Motamedi MH, Khatami SM, Rezaie R, Rasouli HR. Parathyroid hormone measurement in prediction of hypocalcaemia following thyroidectomy. J Coll Physicians Surg Pak. 2014; 24(2):82-87. ${ }^{25}$ Hermann M, Ott J, Promberger R, Kober F, Karik M, Freissmuth M. Kinetics of serum parathyroid hormone during and after thyroid surgery. Br J Surg. 2008; 95(12):1480-1487. ${ }^{26}$ Aluffi P, Aina E, Bagnati T, Toso A, Pia F. Factores pronósticos de hipoparatiroidismo definitivo tras tiroidectomía total [Prognostic factors for definitive hypoparathyroidism following total thyroidectomy]. Acta Otorrinolaringol Esp. 2008; 59(7):321-324. ${ }^{27}$ Kolahdouzan M, Shahabi Shahmiri S, Hashemi SM, Keleidari B, Nazem M, Mohammadi Mofrad R. Is Decline Rate of Intact Parathyroid Hormone Level a Reliable Criterion for Early Discharge of Patients after Total Thyroidectomy?. Iran J Otorhinolaryngol. 2017; 29(94):239-246. ${ }^{28}$ Reddy AC, Chand G, Sabaretnam M, et al. Prospective evaluation of intra-operative quick parathyroid hormone assay as an early predictor of post thyroidectomy hypocalcaemia. Int J Surg. 2016; 34:103-108. ${ }^{29}$ Sosa JA, Tuggle CT, Wang TS, et al. Clinical and economic outcomes of thyroid and parathyroid surgery in children. J Clin Endocrinol Metab. 2008; 93(8):3058-3065. ${ }^{30}$ Klein Hesselink MS, Nies M, Bocca G, et al. Pediatric Differentiated Thyroid Carcinoma in The Netherlands: A Nationwide Follow-Up Study. J Clin Endocrinol Metab. 2016; 101(5):2031-2039. ${ }^{31}$ Dinc T, Kayilioglu SI, Simsek B, et al. The evaluation of the complications observed in patients with bilateral total and bilateral near total thyroidectomy. Ann Ital Chir. 2017; 88:198-201. ${ }^{32}$ Chew C, Li R, Ng MK, Chan STF, Fleming B. Incidental parathyroidectomy during total thyroidectomy is not a direct cause of postoperative hypocalcaemia. ANZ J Surg. 2018; 88(3):158-161. ${ }^{33}$ Ponce de León-Ballesteros G, Velázquez-Fernández D, Hernández-Calderón FJ, et al. Hypoparathyroidism After Total Thyroidectomy: Importance of the Intraoperative Management of the Parathyroid Glands [published correction appears in World J Surg. 2019 Apr 15]. World J Surg. 2019; 43(7):1728-1735. ${ }^{34}$ Overman RE Jr, Hsieh LB, Menon R, Thomas IH, Bruch SW. 4-Hour postoperative PTH level predicts hypocalcemia after thyroidectomy in children. J Pediatr Surg. 2020; 55(7):1265-1269. ${ }^{35}$ Maeda SS, Moreira CA, Borba VZC, et al. Diagnosis and treatment of hypoparathyroidism: a position statement from the Brazilian Society of Endocrinology and Metabolism. Arch Endocrinol Metab. 2018; 62(1):106-124. ${ }^{36}$ Spinelli C, Tognetti F, Strambi S, Morganti R, Massimino M, Collini P. Cervical Lymph Node Metastases of Papillary Thyroid Carcinoma, in the Central and Lateral Compartments, in Children and Adolescents: Predictive Factors. World J Surg. 2018; 42(8):2444-2453. ${ }^{37}$ Zobel MJ, Long R, Gosnell J, Sosa JA, Padilla BE. Postoperative Hypoparathyroidism After Total Thyroidectomy in Children. J Surg Res. 2020; 252:63-68. ${ }^{38}$ Radakrishnan A, Reddy AT, Dalal P, et al. Hypocalcemia prevention and management after thyroidectomy in children: A systematic review. J Pediatr Surg. 2021; 56(3):526-533. ${ }^{39}$ de Jong M, Nounou H, Rozalén García $\mathrm{V}$, et al. Children are at a high risk of hypocalcaemia and hypoparathyroidism after total thyroidectomy. J Pediatr Surg. 2020; 55(7):1260-1264. ${ }^{40}$ Wu SY, Chiang YJ, Fisher SB, et al. Risks of Hypoparathyroidism After Total Thyroidectomy in Children: A 21-Year Experience in a High-Volume Cancer Center. World J Surg. 2020; 44(2):442-451. ${ }^{41}$ Baumgarten HD, Bauer AJ, Isaza A, Mostoufi-Moab S, Kazahaya K, Adzick NS. Surgical management of pediatric thyroid disease: Complication rates after thyroidectomy at the Children's Hospital of Philadelphia high-volume Pediatric Thyroid Center. J Pediatr Surg. 2019; 54(10):1969-1975. ${ }^{42}$ Yu YR, Fallon SC, Carpenter JL, et al. Perioperative determinants of transient hypocalcemia after pediatric total thyroidectomy. J Pediatr Surg. 2017; 52(5):684-688. ${ }^{43}$ Bussières V, Roy S, Deladoey J, Rousseau É, St-Vil D, Piché N. Pediatric thyroidectomy: Favorable outcomes can be achieved by a multidisciplinary team of pediatric providers. J Pediatr Surg. 2019; 54(3):527-530. ${ }^{44}$ Yu YR, Fallon SC, Carpenter JL, et al. Perioperative determinants of transient hypocalcemia after pediatric total thyroidectomy. J Pediatr Surg. 2017;52(5):684-688. ${ }^{45}$ Nordenström E, Bergenfelz A, Almquist M. Permanent Hypoparathyroidism After Total Thyroidectomy in Children: Results from a National Registry. World J Surg. 2018;42(9):2858-2863. ${ }^{46}$ Chadwick DR. Hypocalcaemia and permanent hypoparathyroidism after total/bilateral thyroidectomy in the BAETS Registry. Gland Surg. 2017; 6(Suppl 1):S69-S74. ${ }^{47}$ Scholz S, Smith JR, Chaignaud B, Shamberger RC, Huang SA. Thyroid surgery at Children's Hospital Boston: a 35-year single-institution experience. J Pediatr Surg. 2011; 46(3):437-442. ${ }^{48}$ de Groot JW, Links TP, Rouwe CW, van der Wal JE, Hofstra RM, Plukker JT. Profylactische thyreoïdectomie bij kinderen die drager zijn van een mutatie van multipele endocriene neoplasie type 2: beschrijving van 20 casussen en aanbevelingen op grond van de literatuur [Prophylactic thyroidectomy in children who are carriers of a multiple endocrine neoplasia type 2 mutation: description 
of 20 cases and recommendations based on the literature]. Ned Tijdschr Geneeskd. 2006; 150(6):311-318. ${ }^{49}$ Kluijfhout WP, van Beek DJ, Verrijn Stuart AA, et al. Postoperative Complications After Prophylactic Thyroidectomy for Very Young Patients With Multiple Endocrine Neoplasia Type 2: Retrospective Cohort Analysis. Medicine (Baltimore). 2015; 94(29):e1108. ${ }^{50}$ Moley JF, Skinner M, Gillanders WE, et al. Management of the Parathyroid Glands During Preventive Thyroidectomy in Patients With Multiple Endocrine Neoplasia Type 2. Ann Surg. 2015; 262(4):641-646. ${ }^{51}$ Hauch A, Al-Qurayshi Z, Randolph G, Kandil E. Total thyroidectomy is associated with increased risk of complications for low- and high-volume surgeons. Ann Surg Oncol. 2014; 21(12):3844-3852. ${ }^{52}$ Newman KD, Black T, Heller G, et al. Differentiated thyroid cancer: determinants of disease progression in patients $<21$ years of age at diagnosis: a report from the Surgical Discipline Committee of the Children's Cancer Group. Ann Surg. 1998; 227(4):533-541. ${ }^{53}$ Spinelli C, Rallo L, Morganti R, et al. Surgical management of follicular thyroid carcinoma in children and adolescents: A study of 30 cases. J Pediatr Surg. 2019; 54(3):521-526. ${ }^{54}$ Sitges-Serra A, Ruiz S, Girvent M, Manjón H, Dueñas JP, Sancho JJ. Outcome of protracted hypoparathyroidism after total thyroidectomy. Br J Surg. 2010; 97(11):1687-1695. ${ }^{55}$ Wells SA Jr, Gunnells JC, Shelburne JD, Schneider AB, Sherwood LM. Transplantation of the parathyroid glands in man: clinical indications and results. Surgery. $1975 ; 78(1): 34-44 .^{56}$ Su A, Gong Y, Wu W, Gong R, Li Z, Zhu J. Does the number of parathyroid glands autotransplanted affect the incidence of hypoparathyroidism and recovery of parathyroid function? [published online ahead of print, 2018 Feb 2]. Surgery. 2018; S0039-6060(17)30928-5. ${ }^{57}$ Lorente-Poch L, Sancho J, Muñoz JL, Gallego-Otaegui L, Martínez-Ruiz C, Sitges-Serra A. Failure of fragmented parathyroid gland autotransplantation to prevent permanent hypoparathyroidism after total thyroidectomy. Langenbecks Arch Surg. 2017; 402(2):281-287.

\section{Hosted file}

Table 1.docx available at https://authorea.com/users/325851/articles/524530-factorsassociated-with-postoperative-hypocalcemia-following-surgery-for-thyroid-cancer-inchildhood

\section{Hosted file}

Table 2.docx available at https://authorea.com/users/325851/articles/524530-factorsassociated-with-postoperative-hypocalcemia-following-surgery-for-thyroid-cancer-inchildhood 